\title{
SuPer-Heróis MANIFESTANTES? Simbolismos DA CULTURA POP PERFORMATIZADOS EM MOVIMENTOS SOCIAIS
}

\author{
Aline Eggres de CASTRO* \\ Rosana PINHEIRO-MACHADO**
}

\begin{abstract}
RESUMO: As manifestações populares dos últimos anos foram marcadas não apenas pela multiplicidade de demandas, pela moralidade das ideias e pela influência das redes sociais na mobilização de um grande número de pessoas - elas também trouxeram um novo perfil de jovens manifestantes que utilizam estratégias lúdicas de humor e performances culturais que afirmam sua identidade pessoal em meio a sua atuação política. O presente estudo pretende analisar a influência da chamada cultura pop nas formações identitárias e morais desses jovens, bem como demonstrar que suas performances não são aleatórias, mas sim carregadas de simbolismos.
\end{abstract}

PALAVRAS-CHAVE: Novíssimos movimentos sociais. Moral. Performance. Cultura pop. Identidade.

Introdução

O século XXI tem sido marcado por inúmeras alterações na ordem social ocasionadas por manifestações em diversas partes do globo (mundo árabe, norte da África, EUA, Espanha, Brasil, entre outros) que reivindicam questões que vão desde a libertação de ditaduras opressoras até o impedimento do aumento nas tarifas de ônibus. Movimentos como a Primavera Árabe, Occupy Wall Street, Jornadas de Junho e Indignados causaram alterações não apenas nas ordens política, social e econômica, como também no campo simbólico, ao apresentar inúmeros novos repertórios de expressão por parte dos manifestantes - repertórios os quais se perpetuaram por

\footnotetext{
* UFSM - Universidade Federal de Santa Maria. Santa Maria - RS - Brasil. 97105-900. alineeggres@gmail.com. https://orcid.org/0000-0002-7249-1414.

** University of Bath. Bath - Somerset - Reino Unido. BA2 7AY. - rpinheiromachado@yahoo.com.br. https://orcid.org/0000-0002-4440-8441.
} 
movimentos posteriores, como as passeatas a favor e contra o impeachment da presidenta Dilma Rousseff no Brasil e os protestos contra o porte de armas nos Estados Unidos.

As novas formas de manifestação ficaram conhecidas na literatura como "novíssimos movimentos sociais" e trazem características que as diferenciam de manifestações anteriores. Nesse novo momento, o ativismo alcançou escalas globais, com protestos contemporâneos que envolvem pessoas e temas os quais atravessam fronteiras e se dirigem, muitas vezes, a instituições multilaterais ou a uma opinião pública transnacional. As pautas são consideradas pós-materiais, com mobilizações étnicas, religiosas, comunitárias e conservadoras (ALONSO, 2009). O antigo antagonismo capital vs. trabalho é substituído pelo antagonismo tecnocratas vs. movimentos sociais (JASPER, 2016).

Este estudo visa analisar essas novas formas de manifestação, suas influências e as maneiras como os novos manifestantes se expressam. Para isso, são discutidos o que são essas novas manifestações, quem são esses manifestantes e qual o papel que a cultura e a moralidade exercem nesses movimentos. Por fim, são apresentados exemplos reais de manifestações políticas que ilustram os temas discutidos.

\section{Os novíssimos movimentos sociais e suas manifestações performáticas}

O objetivo dos novíssimos movimentos sociais, de acordo com Day (2004), não é criar um novo poder em torno de um centro hegemônico, dando continuidade às políticas de demanda, mas sim desafiar, desorganizar e desorientar os processos de hegemonia global, fazendo na prática as políticas do ato. Esses novíssimos manifestantes ou novos anarquistas ${ }^{2}$, como os chama Graeber (2002) devido às suas características insurgentes, exploram as possibilidades de formas não hegemônicas de mudança social radical. Suas táticas de ação direta e participativa prefiguram alternativas às formas hegemônicas estatais e corporativas. Um exemplo desse tipo de ação direta são as mídias independentes, que visam combater a concentração empresarial na propriedade dos meios de comunicação através da criação de fontes alternativas de informação (DAY, 2004).

\footnotetext{
${ }^{1}$ Newest social movements (DAY, 2004).

2 Day (2004) ressalva que nem todo indivíduo ou todo grupo que participa do ativismo radical contemporâneo se identifica dessa maneira; o próprio Graeber (2002) afirma que poucos se declaram como anarquistas, mas ele trata dessa forma pelo fato de o anarquismo ser o coração do movimento.
} 
A forma de ação direta que tem sido mais amplamente utilizada é a reunião de grandes grupos em locais públicos, em movimentos como marchas e ocupações. Butler (2011) afirma que, quando esses corpos se reúnem, eles se movem e falam juntos por meio de uma performatividade do corpo que atravessa a linguagem sem nunca se reduzir à linguagem. Esses corpos reivindicam não apenas os seus propósitos políticos, mas também o próprio direito de ocupar aquele espaço público.

Essa performatividade é expressa por meio dos repertórios de ação coletiva, que constituem as diferentes formas de manifestação (maneiras ou padrões com as quais as pessoas sabem aplicar determinadas ferramentas a partir de sua história particular), que se transformam com o desenvolvimento da sociedade. Os repertórios de ações coletivas evoluem de duas maneiras: o conjunto de meios disponíveis para as pessoas muda em função das transformações sociais, econômicas e políticas, enquanto cada meio individual de ação se adapta a novos interesses e novas oportunidades de ação (TILLY, 1977).

Os repertórios desses novíssimos movimentos sociais se diferenciam de movimentos anteriores pela influência do transnacionalismo e da globalização (TARROW, 2005), pelo emprego de redes sociais combinadas com outros aplicativos da web e ferramentas de Internet (DELLA PORTA, 2014; CASTELLS, 2015) e pelas lógicas de agregação provocadas por essa rede de grande alcance (JURIS, 2012). A sociedade em rede, com a disseminação e troca multilateral de informações e opiniões a uma velocidade nunca vista antes, é algo inédito trazido pela era da Internet, que permite que manifestantes se comuniquem livremente sobre suas causas e suas formas de se manifestar.

Essa difusão de repertórios - especialmente as performances nas ruas - compõe o que Calhoun (2013) chama de idealismo performático (ou dramático), que ajuda a criar momentos nos quais o ativismo tem altos picos de atividade, causados pela inspiração nos demais movimentos. Por se tratar de performance, entende-se que a forma de expressão desses corpos é fortemente influenciada pela cultura das quais eles fazem parte e as quais consomem no seu dia a dia. Para compreender melhor o tipo de cultura que se disseminou nos novíssimos movimentos sociais, é importante saber quem eram esses corpos performáticos.

\section{Quem são os "novíssimos" ativistas?}

Pesquisas sobre o perfil dos participantes de protestos do século XXI, caracterizados como novíssimos movimentos sociais, demonstram que havia pessoas de 
todas as idades e condições sociais ocupando ruas e locais públicos (CASTELLS, 2015; GUZMAN, 2011; BRAGA, 2016). O perfil predominante entre essas multidões, no entanto, era de jovens ${ }^{3}$ no fim da adolescência e início da idade adulta (GONÇALVES; BARBOSA, 2016; GUZMAN, 2011), usuários ativos de redes sociais (CASTELLS, 2015) que possuíam uma lógica de agregação por meio dessas redes (JURIS, 2012).

Esse perfil condiz com o que Howe e Strauss $(1992,2000)$ denominaram como Millennials, isto é, as pessoas nascidas entre o início dos anos 1980 e meados dos anos 1990 - ou seja, aqueles que iniciavam sua maturidade no início do novo milênio. Os autores caracterizam as pessoas dessa geração como otimistas; cooperativas em equipe - com mentalidade coletiva; crentes no futuro e neles mesmos como criadores de um futuro melhor; criativos; com autoestima elevada (podendo ser interpretado como narcisismo em certas ocasiões); mais formalmente educados, inclusivos e a favor da diversidade que a geração anterior; críticos em relação às regras sociais; e influenciados pela ascensão da Internet no período de sua maturidade.

Melucci (2007) acredita que os jovens estão no centro de qualquer movimento social:

Começando pelo movimento estudantil dos anos 60 é possível traçar a participação juvenil em movimentos sociais pelas formas "subculturais" de ação coletiva nos anos 70 como os punks, os movimentos de ocupação de imóveis, os centros sociais juvenis em diferentes países europeus, pelo papel central da juventude nas mobilizações pacifistas e ambientais dos anos 80 , pelas ondas curtas mas intensas de mobilização de estudantes secundaristas dos anos 80 e começo dos 90 (na França, Espanha e Itália, por exemplo) e, finalmente, pelas mobilizações cívicas nos anos 90 como o antirracismo no norte da Europa, França e Alemanha ou o movimento da antimáfia na Itália. Todas estas formas de ação envolvem pessoas jovens como atores centrais; mesmo se apresentam diferenças históricas e geográficas com o passar das décadas, elas dividem características comuns que indicam um padrão emergente de movimentos sociais em sociedades complexas, pós-modernas. (MELUCCI, 2007, p.40).

Assim como os jovens manifestantes dos anos 1970 foram fortemente influenciados pela cultura "punk" (MELUCCI, 2007), os jovens do século XXI sofrem influência da cultura "pop" - amplamente disseminada na sociedade - em suas

\footnotetext{
3 Faixa etária predominante nas manifestações: estimada entre 17 a 28 anos por Gonçalves e Barbosa (2016), que estudaram movimentos no Brasil; e entre 18 e 34 anos por Guzman (2011), que estudou movimentos nos EUA.
} 
performances (AMARAL, 2014). Essa influência da cultura pop interfere tanto na criação da identidade desses grupos como na sua atuação política.

\section{A cultura pop e a construção de identidades}

O termo pop, abreviação de popular, é amplamente utilizado para classificar produtos, fenômenos, artistas, lógicas e processos midiáticos. Soares (2014) atribui o termo cultura pop ao conjunto de práticas, experiências e produtos norteados pela lógica midiática, que tem como gênese o entretenimento; ancora-se, em grande parte, em modos de produção ligados às indústrias da cultura (música, cinema, televisão, editorial, entre outras) e estabelece formas de fruição e consumo que permeiam um certo senso de comunidade, pertencimento ou compartilhamento de afinidades que situam indivíduos dentro de um sentido transnacional e globalizante.

Estar imerso na cultura pop é se estender por objetos que falam por clichês, por frases de efeito, arranjos musicais excessivamente difundidos, filmes cujos finais já se sabe, canções cujos versos já foram ouvidos, refrãos impactantes, cenas de novela que fazem chorar, entre outros (SOARES, 2014). O gosto pelos produtos da cultura pop costuma gerar paixões naqueles que os admiram - os fãs -, fazendo com que a manifestação dessa preferência ultrapasse o simples consumo midiático desses produtos. Amaral (2014) aponta que o gosto não pode ser desvinculado das materialidades e suportes pelos quais eles circulam e dos modos pelos quais esses objetos nos afetam. O gosto seria, portanto, uma performance, que demonstra para o mundo os elementos pelos quais os indivíduos sentem afinidade.

Essas performances podem ser vistas em diversas ocasiões do dia a dia, como no uso de camisetas de bandas, nas decorações com imagens de personagens de filmes, nos utensílios domésticos com estampas de super-heróis, em materiais escolares com licenciamento de personagens de desenhos animados, entre outros. A ascensão e expansão de lojas virtuais como Nerd Store, Loja Mundo Geek, Omelete Store e Oba Shop, destinadas a esse tipo de produto, comprova a crescente busca pela performance de identidade cultural ${ }^{4}$.

A identidade é vista por Bauman (2004) como uma tarefa - uma tarefa ainda não realizada, incompleta, um estímulo, um dever e um ímpeto à ação. Nascida como

\footnotetext{
${ }^{4}$ Identidade cultural: termo difundido por Stuart Hall (2006) ao tratar das mudanças estruturais que fragmentam e desconstroem as identidades culturais de classe, etnia, raça, nacionalidade e gênero na pós-modernidade.
} 
ficção, a identidade precisava de muita coerção e convencimento para se consolidar e se concretizar numa realidade. A busca pela autoidentidade, para Giddens (2002), é um problema moderno, provavelmente originado no individualismo ocidental. A ideia de que cada pessoa tem um caráter único e potencialidades sociais que podem ou não se realizar é alheia à cultura pré-moderna. Perguntas como $\mathrm{O}$ que fazer? Como agir? e Quem ser? são centrais para quem vive nas circunstâncias da modernidade tardia, e elas são respondidas por todos, seja no discurso, seja no comportamento cotidiano.

Para o sujeito pós-moderno, a identidade torna-se uma celebração móvel, formada e transformada continuamente em relação às formas pelas quais somos representados ou interpelados nos sistemas culturais que nos rodeiam (HALL, 2006). O sentido de identidade passa a ser encontrar-se a si mesmo. As transformações na autoidentidade e a globalização são dois polos da dialética do local e do global nas condições da alta modernidade. Em outras palavras, mudanças em aspectos íntimos da vida pessoal estão diretamente ligadas ao estabelecimento de conexões sociais de grande amplitude. O nível do distanciamento tempo-espaço introduzido pela alta modernidade é tão amplo que, pela primeira vez na história humana, "eu" e "sociedade" estão interrelacionados num meio global (GIDDENS, 2002). A identidade pessoal passa a ser influenciada, portanto, pelas coletividades.

A identidade coletiva é, segundo Melucci (2001), uma definição construída e negociada pela ativação das relações sociais entre os atores. Ela implica a presença de quadros cognitivos de densas interações e também das dimensões efetivas e emocionais. A ação coletiva de um movimento é construída por meio de relações sociais no interior de um campo de oportunidades e de vínculos, dando sentido ao seu agir comum e aos objetivos que perseguem.

Essas conexões necessárias para a formação de uma identidade coletiva e o esforço para cumprir um senso de pertencimento a um grupo explica os padrões de difusão massiva da cultura pop, bem como os padrões de difusão de imagens ocorridos nos novíssimos movimentos. Representações simbólicas, muitas vezes utilizando-se de elementos da cultura pop - como a máscara de Guy Fawkes ${ }^{5}$-, foram reproduzidas como por contágio de país a país - bem como ideias e táticas, quadros e estratégias (DELLA PORTA, 2014) - ou seja, havia a difusão dos repertórios (TILLY, 1977). Os repertórios relacionados à cultura pop utilizados em manifestações dificilmente são

\footnotetext{
${ }^{5}$ Guy Fawkes foi um inglês condenado à morte por participar da Conspiração da Pólvora. Sua máscara, criação de David Lloyd, da HQ V de Vingança, foi adotada em 2008 pelo movimento hacker Anonymous e se tornou um símbolo de 2011, quando foi visto em protestos por todo o mundo (SUPER INTERESSANTE, 2016).
} 
escolhidos ao acaso - eles são frutos de um conteúdo que inspira seus fãs a lutar por um mundo melhor.

\section{A cultura pop e a moral}

Um dos mais notáveis desenvolvimentos na cultura pop atual é o ressurgimento dos super-heróis como ícones culturais e de entretenimento. Mas suas histórias não trazem apenas divertimento, elas também expõem de forma perspicaz questões referentes à ética e à moral ${ }^{6}$, que todos enfrentamos no dia a dia. Temas como responsabilidade pessoal e social, justiça, compaixão, crime e castigo, noções de destino e sentido da vida e virtudes como a coragem são amplamente abordados de forma vívida nessas histórias. A exposição a esses conteúdos tende a inspirar a formação da consciência moral dos jovens que as acompanham (WESCHENFELDER, 2012).

Não apenas os personagens com capa e identidade secreta inspiram reflexões morais e éticas nos jovens apreciadores da cultura pop. Diversos outros personagens de filmes e livros que enfrentam diferentes adversidades servem como exemplo de conduta para seus consumidores. Um exemplo notório que acompanhou o crescimento da geração dos Millennials foi a saga Harry Potter - na qual um garoto de apenas onze anos descobre que é um bruxo e se vê destinado a combater forças malignas. Anderson (2018) aponta que, por baixo da açucarada iconografia da série Harry Potter, a narrativa aborda temas pesados, como limpeza étnica, desigualdade, escravidão, governos corruptos e tortura. Em sua essência, os livros Harry Potter tratam do bem contra o mal.

Todas essas histórias que antagonizam o herói e o vilão ou criam suas próprias distinções (como a "luz" e o "lado sombrio da força" na franquia Star Wars) expõem o espectador a uma reflexão sobre a oposição entre o bem e o mal. Esses repertórios culturais acabam por influenciar a identidade e a personalidade dos indivíduos de acordo com a interpretação que cada um leva daquilo que consumiu. Esses repertórios passam a ser utilizados em outras manifestações além das culturais, como nos atos políticos, nos quais manifestantes utilizam-se de frases e imagens desses ícones da cultura para representarem a si mesmos enquanto atores políticos.

\footnotetext{
${ }^{6}$ A ética está associada ao estudo fundamentado dos valores morais que orientam o comportamento humano em sociedade, enquanto a moral são os costumes, regras, tabus e convenções estabelecidas por cada sociedade.
} 


\section{Moral e protestos do século XXI}

As múltiplas demandas dos protestos que marcaram o início do novo milênio, especialmente os anos 2010, fizeram com que muitos espectadores pensassem neles como movimentos sem uma ideologia; que se tratavam de "rebeldes sem causa" por não possuírem um foco unificado. Apesar de cada grupo defender diferentes pautas, uma característica que quase todos os protestos têm em comum é clara: as manifestações pelo mundo têm uma origem moral. Weiss (2014) considera os novíssimos movimentos como a expressão de uma insatisfação com os padrões morais vigentes que estruturam a dinâmica econômica, política e mesmo a das relações pessoais, e em cada contexto social específico uma ou outra dimensão ganhou mais relevo.

No Brasil, como em outras partes do mundo, é possível entender as manifestações como uma resposta à não realização de ideais que foram transmitidos, como se fosse um distanciamento entre os discursos e a prática, entre princípio ideal e a realidade. Nessa perspectiva, trata-se de um mundo cada vez mais sem significado, no qual os valores são desrespeitados e ignorados de forma sistemática (WEISS, 2014).

Os movimentos sociais podem ser vistos em muitos casos, portanto, como movimentos morais. Tipicamente, os ativistas envolvidos neles tentam confrontar e mudar não apenas as opiniões políticas de seus destinatários, mas também as convicções morais que formam essas opiniões. Ativistas podem ser vistos como seguidores e perseguidores de ideais. Para transmitir com sucesso a sua mensagem e conquistar novos adeptos, os movimentos devem, portanto, enfatizar a sua identidade como seguidores de ideais (JACOBSSON; LINDBLOM, 2012).

A cultura da Internet e das redes sociais, que criou uma nova forma de interação como um novo padrão de sociabilidade, é bastante propícia para a criação de novos valores morais: ela permite uma aproximação entre indivíduos que compartilham convicções semelhantes e que não se encontrariam de outro modo, pois, em termos de estruturas tradicionais (trabalho, religião, classe social etc.), fariam parte de grupos muito diferentes. Essas interações promovem o que, por uma perspectiva durkheimiana (DURKHEIM, 2002), pode ser interpretado como um efeito dinamogênico proporcionado por essa intensa experiência de efervescência. A dinamogenia é o efeito de aumento de energia promovido por uma situação de super excitação. É o que dá aos indivíduos a sensação de que são mais fortes e mais capazes quando vivenciam situações coletivas desse tipo e faz com que os valores criados ou debatidos naquele contexto sejam investidos de uma aura particular, de grande importância (WEISS, 2014). 


\section{Repertórios culturais e mobilização política}

Um fenômeno notório e crescente nas mobilizações contemporâneas é a viralização de material de cunho fanmade $^{7}$, que ultrapassa a barreira do fandom $^{8}$, tornase mainstream ${ }^{9}$ e é utilizado em movimentos sociais, como nos protestos em junho de 2013 no Brasil, por exemplo. Práticas comuns, como remixagens de imagens, memes, cartazes, fanvideos e fanarts, relacionados à cultura pop global passaram a integrar cartazes com dizeres relacionados a diferentes elementos culturais e tornaram-se comuns nas manifestações, corroborando a apropriação da cultura pop, usualmente associada a fãs e atividades desimportantes, por movimentos sociopolíticos (AMARAL; SOUZA; MONTEIRO, 2014). Esses materiais passam a compor o repertório desses manifestantes, que querem transpor sua identidade e seus gostos pessoais para diversas áreas de sua vida - inclusive para sua atuação política.

Amaral, Souza e Monteiro (2014) chamam de ativismo de fãs essa intersecção entre ativismo e engajamento político no domínio dos fandoms, sobretudo relacionados aos produtos e celebridades da cultura pop. Nesse sentido, a cultura dos fãs influencia a participação política e o exercício da cidadania, os quais vêm sendo manifestados, de forma crescente, por exemplo, por meio da cultura remix e da produção de memes. A mídia também começa a perceber tais manifestações e utilizá-las como forma de caracterização dos participantes em manifestações: "O caldeirão cultural que alimenta os protestos mistura política e publicidade, heróis da Marvel, Maio de 68, poesia concreta, e a surrada máscara de "V de Vingança"” (WERNECK; MARTÍ 2013).

Os movimentos contemporâneos da juventude usam formas de representação como o teatro, o vídeo e a mídia, fazendo com que a mensagem tome uma forma de reprodução simbólica. Eles são um laboratório no qual novos modelos culturais, formas de relacionamento e pontos de vista alternativos são testados e colocados em prática (MELUCCI, 2007). Os manifestantes buscam aproveitar o palco, produzir dramas sociais e projetá-los com sucesso para o público (ALEXANDER, 2017).

Alexander (2016) argumenta que os teóricos sociais devem usar as ferramentas da dramaturgia, da teoria do drama e da crítica teatral para desenvolver uma sociologia cultural da performance social e, com ela, uma nova sociologia da modernidade. $\mathrm{O}$ autor conceitua o ritual como um tipo particular de performance social, altamente bemsucedida, na qual atores, público e roteiro se fundem. Aqueles que assistem à

\footnotetext{
${ }^{7}$ Obras feitas por pessoas que não são detentoras dos direitos autorais.

${ }^{8}$ Comunidades de fãs que compartilham gostos em comum.

${ }_{9}^{9}$ Pensamento comum, convencional.
} 
performance não a veem como uma performance; eles se identificam com os protagonistas e sentem inimizade pelos antagonistas no palco; eles perdem a sensação de ser uma audiência, experimentando não a artificialidade, mas sim a verossimilhança. A quarta parede do drama, que existe não apenas dentro do teatro, mas também fora dele, na sociedade, quebra ou é quebrada.

Essas performances simbólicas vão ao encontro do que Goffman (1990) denominou como "encenação dramatúrgica" - ou teatral - na interação coletiva. Quando na presença de outros, o indivíduo transmite sinais do self - de sua autorrepresentação -, que destacam dramaticamente fatos confirmatórios daquilo que, de outra forma, poderia permanecer despercebido. Se o indivíduo deseja tornar significativa sua atividade para os outros, ele deve mobilizar seus esforços de modo que expressem, durante a interação, o que se deseja transmitir.

Exemplos dessas performances dramáticas, que trazem simbolismos da cultura pop enfatizando a identidade dos manifestantes, são apresentados nas figuras a seguir. Todas elas retratam ações coletivas diretas que mobilizaram um grande número de pessoas em torno de uma causa específica ou em defesa de múltiplas causas.

Figura 1 - Manifestantes com máscaras de Guy Fawkes

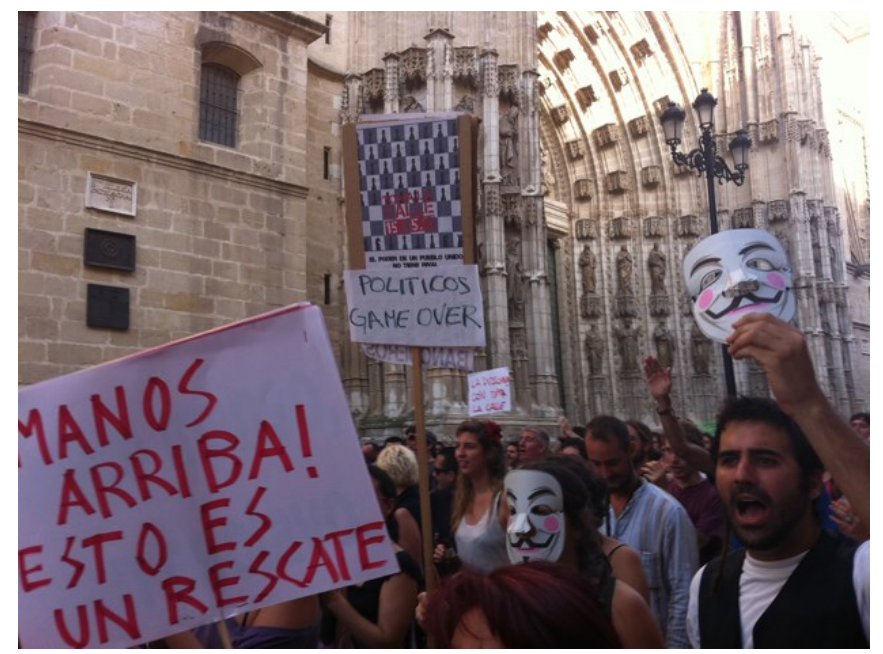

Fonte: Taringa, 2012.

Manifestantes espanhóis do movimento Indignados, de 2011, estão com as máscaras de Guy Fawkes, mencionadas na seção anterior, nessa Figura 1. Assim como Guy Fawkes tinha a intenção de destituir o poder dominante, o movimento Indignados iniciou com pautas relacionadas a mudanças na política e na sociedade espanhola - 
pautas claramente de cunho moral. No decorrer dos protestos, surgiu uma série de outras reivindicações de ordem política, econômica e social heterogêneas - demonstrando a multiplicidade característica dos novíssimos movimentos.

Figura 2 - Cartaz com dizeres de Pokémon

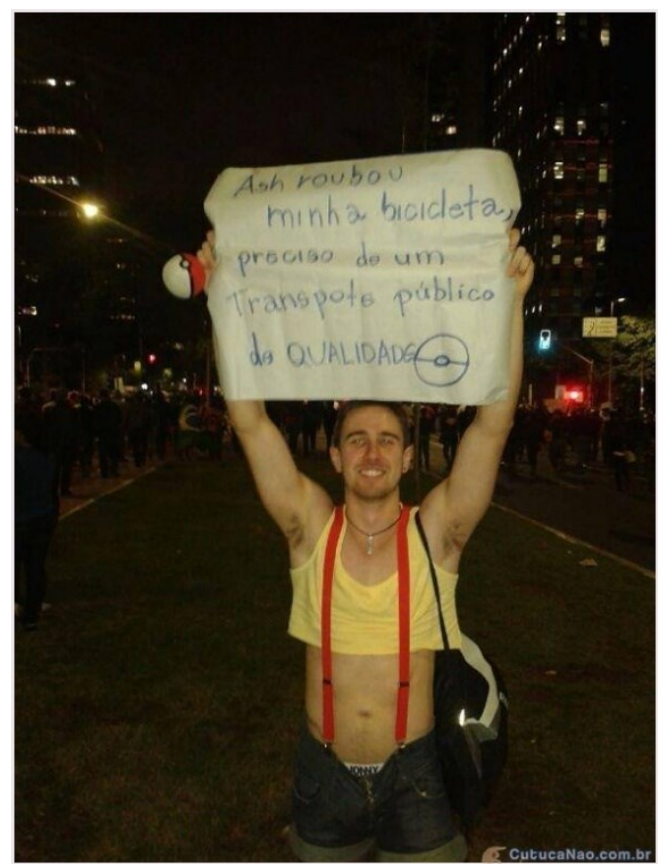

Fonte: Amaral, Souza e Monteiro, 2014.

A Figura 2 é a foto de um manifestante de São Paulo nos protestos que ficaram conhecidos no Brasil como Jornadas de Junho - que começaram com a pauta da redução no valor da passagem do transporte público, mas logo englobaram diversas outras pautas relacionadas à economia, educação, justiça, política, entre outras. Para exigir um transporte público de qualidade, o jovem faz referência ao episódio do anime Pokemón em que o personagem Ash, ao ter dificuldades para se locomover até um centro Pokemón, rouba a bicicleta da personagem Misty (a qual o manifestante representa com seu cosplay $\left.{ }^{10}\right)$. No anime, o espectador frequentemente se depara com lições de moral dos tipos: "o crime não compensa" e "é preciso um grande esforço para alcançar seus objetivos".

10 Termo em inglês, formado pela junção das palavras costume (fantasia) e roleplay (brincadeira ou interpretação). Refere-se ao hábito de se vestir como personagens fictícios. 
Figura 3 - Cartaz com dizeres de Game of Thrones

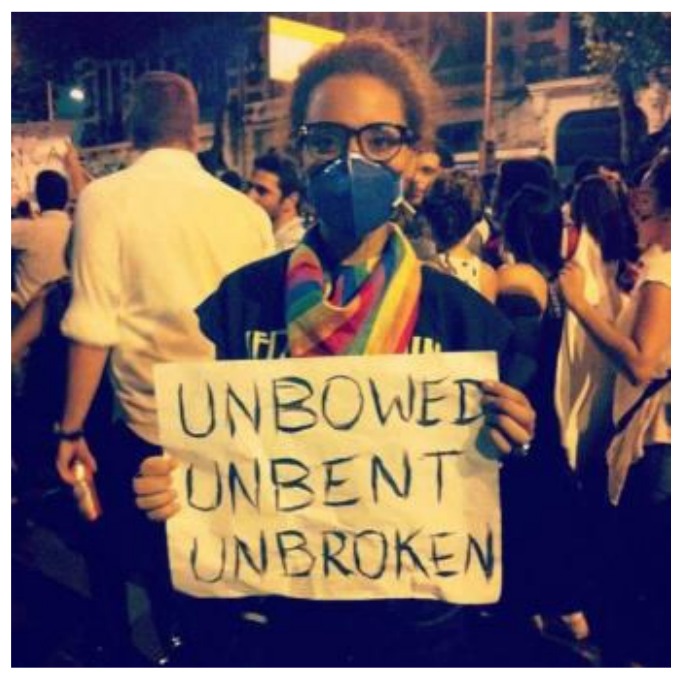

Fonte: Amaral, Souza e Monteiro, 2014.

Na Figura 3, há uma manifestante do Rio de Janeiro, também nas Jornadas de Junho, com os dizeres "Unbowed, Unbent, Unbroken" ("insubmissos, não curvados, inquebráveis") - lema da Casa Martell da série de livros As Crônicas de Gelo e Fogo ${ }^{11}$ e da série televisiva Game of Thrones. A Casa Martell é notória na trama por buscar justiça pelos membros de sua família que foram prejudicados no passado.

Figura 4 - Manifestantes fantasiados de super-heróis

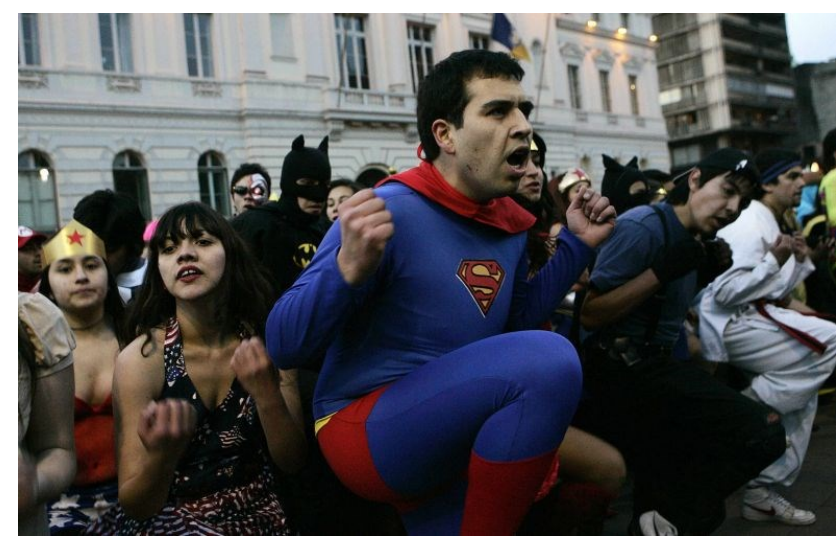

Fonte: UOL Educação, 2011.

${ }^{11}$ MARTIN, George R.R. As Crônicas de Gelo e Fogo. 5 volumes. 1. ed. Rio de Janeiro: Leya, 2015. 
Em 2011, no Chile, manifestações foram realizadas, a nível nacional, por estudantes universitários e secundaristas em defesa da educação pública. O movimento ficou conhecido como La Revolución Pingüina (Revolução dos Pinguins) devido ao tradicional uniforme utilizado pelos estudantes. Os manifestantes sofreram violenta repressão do governo conservador de Sebastián Piñera - a polícia utilizou-se de balas de borracha e gás lacrimogêneo e realizou 133 detenções. Em resposta, alguns manifestantes trocaram seu tradicional uniforme "pinguim" pelo uniforme de superheróis dos quadrinhos, como na Figura 4, em que os manifestantes representam Superman, Batman e Mulher Maravilha - membros da equipe Liga da Justiça, que se reúne para defender pessoas inocentes de ameaças malignas.

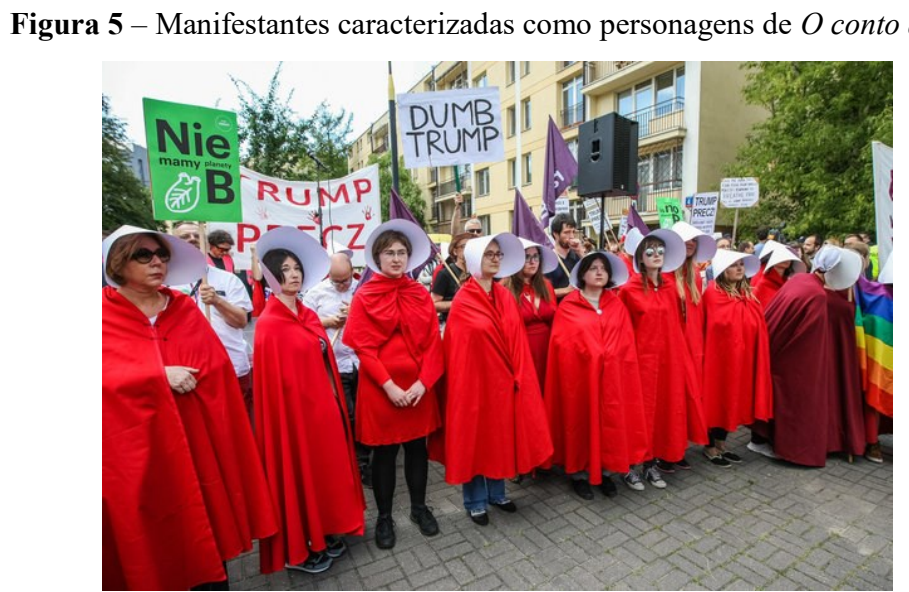

Fonte: VAGIANOS, 2017.

Mulheres polonesas se fantasiaram como aias fazendo referência ao livro $O$ conto da aia, de Margaret Atwood, e à série de televisão The Handmaid's Tale, baseada nele, para protestar contra Donald Trump, de passagem pela Polônia em 2017 para o encontro do G20 na Alemanha, em função de um projeto de lei que poderia proibir o aborto nos EUA. No mesmo ano, a Polônia também discutia as legislações relativas ao aborto em seu país, resultando, em 2018, em um enrijecimento da lei - proibição do aborto inclusive em casos de má formação do feto. O livro referenciado consiste em um mundo distópico onde as poucas mulheres que ainda são férteis após desastres nucleares são escravizadas por famílias ricas para gerarem filhos saudáveis. Na história, o aborto é considerado um pecado e um crime gravíssimo, punível com morte. 
Figura 6 - Cartaz com dizeres de Harry Potter ${ }^{12}$

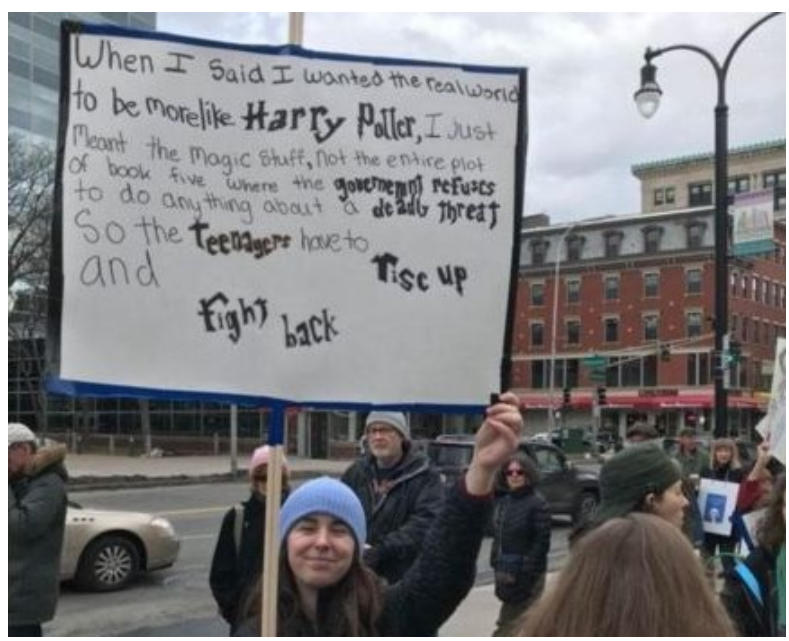

Fonte: Peter Hansen, publicada em Anderson, 2018.

A Figura 6, por fim, apresenta uma jovem fã da saga Harry Potter, que trata do protagonismo de adolescentes contra forças malignas quando o ministério se recusa a acreditar que haja uma ameça real, protestando na Marcha Pelas Nossas Vidas movimento contra o porte de armas, que teve mais de 800 manifestações nos Estados Unidos e em outros países em março de 2018, motivados por tiroteios em escolas e pelo exorbitante número de incidentes com armas de fogo nos últimos anos. O presidente dos EUA, Donald Trump, em diversas oportunidades, evitou tratar do assunto na mídia.

\section{Considerações finais}

Os casos apresentados demonstram que os conteúdos admirados e representados pelos manifestantes são carregados de simbolismos. Eles não são escolhidos por acaso, mas sim por uma identificação do jovem protestante com um personagem da cultura pop que passa por uma situação semelhante à que ele vivencia no mundo real. Esses

\footnotetext{
12 "Quando disse que queria que o mundo real fosse mais como o de Harry Potter, eu me referia às coisas mágicas, não ao enredo inteiro do livro cinco, em que o governo se recusa a fazer qualquer coisa a respeito de uma ameaça de morte levando os adolescentes a se organizar para revidar" (tradução nossa).
} 
conteúdos os inspiram a buscar uma melhoria na sociedade da mesma forma que os personagens buscam na ficção.

Ao se reunirem em grupos com uma formação identitária semelhante, o sentimento de poder fazer algo parece se exaltar, como já explicava a teoria da efervescência coletiva de Durkheim (2002). Os manifestantes utilizam seus repertórios culturais pessoais para perfomatizar as suas demandas e criam momentos de pico de atividade, nos quais todos parecem ter esperanças naquilo pelo qual lutam.

Mesmo pessoas que não pertencem a esses grupos, ao ter acesso a essas performances pelas redes sociais e por outros meios na Internet ou até nas mídias tradicionais, podem se sentir mobilizadas pela criatividade e pelo humor utilizados por esses manifestantes, gerando o contágio que faz com que essas mobilizações cresçam exponencialmente. $\mathrm{O}$ humor e a criatividade são características marcantes dessa jovem geração de ativistas, que utilizam referências da cultura pop, memes e mídias diversas e não têm medo de desafiar os seus dirigentes com manifestações ousadas e desafiadoras do poder hierárquico.

Apesar da grande repercussão dessas atividades, é preciso que os manifestantes tomem cuidado para que o performismo não se torne miúdo e fugaz diante das complexas formas de dominação e controle social contra as quais protestam. Mais importante que a performance em si deve ser sempre o conteúdo carregado por ela.

A formação política desses jovens se dá em torno dessas experiências e dessas identidades culturais. É uma geração moldada pela moralidade no conteúdo que consome e nas manifestações de que participa. Só podemos esperar que essa moralidade seja refletida em um comportamento ético nas suas futuras atuações políticas e nos demais aspectos de suas vidas cotidianas, para que possam trazer mudanças reais na sociedade de que fazem parte.

\section{DEMONSTRATOR SUPERHEROES? SYMBOLISMS OF POP CULTURE PERFORMED IN SOCIAL MOVEMENTS}

ABSTRACT: Popular demonstrations in recent years have been marked not only by the multiplicity of demands, morality of ideas and the influence of social networks on the mobilization of large numbers of people - they have also brought a new profile of young protesters using playful strategies of humor and cultural performances which affirm their personal identity in the midst of their political acting. This study aims to analyze the influence of "pop culture" on these young people's identity and moral characters, as 
well as to demonstrate that their performances are not random, but loaded with symbolism.

KEYWORDS: Newest social movements. Moral. Performance. Pop culture. Identity.

\section{¿SUPERHÉROES MANIFESTANTES? SimbOLISMOS DE LA CULTURA POP REPRESENTADO EN MOVIMIENTOS SOCIALES}

RESUMEN: Las manifestaciones populares de los últimos años han estado marcadas no sólo por la multiplicidad de demandas, la moralidad de las ideas y la influencia de las redes sociales en la movilización de un gran número de personas, sino que también han traído un nuevo perfil de jóvenes manifestantes que utilizan estrategias lúdicas de humor y actuaciones culturales que afirman su identidad personal en medio de su actuación política. Este estudio tiene como objetivo analizar la influencia de la llamada cultura pop en las formaciones morales y de identidad de estos jóvenes, así como demostrar que sus actuaciones no son aleatorias, sino que están cargadas de simbolismo.

PALABRAS CLAVE: Nuevos movimientos sociales. Moral. Performance. Cultura pop. Identidad.

\section{REFERÊNCIAS}

ALEXANDER, Jeffrey C. Seizing the Stage: Social Performances from Mao Zedong to Martin Luther King Jr., and Black Lives Matter Today. TDR: The Drama Review, Vol. 61, nº 1, 2017.

ALEXANDER, Jeffrey C. Performance and Politics: President Obama's Dramatic Reelection in 2012. TDR: The Drama Review, Vol. 60, nº 4, 2016.

ALONSO, Angela. As teorias dos movimentos sociais: um balanço do debate. Lua Nova, São Paulo, 76: 49-86, 2009.

AMARAL, Adriana. Manifestações da performatização do gosto nos sites de redes sociais: uma proposta pelo olhar da cultura pop. Revista ECOPÓS. V. 17, n. 3, 2014.

AMARAL, Adriana; SOUZA, Rosana V.; MONTEIRO, Camila. "De Westeros no \#vemprarua à shippagem do beijo gay na TV brasileira". Ativismo de fãs: conceitos, resistências e práticas na cultura digital brasileira. Anais do Intercom - Sociedade Brasileira de Estudos 
Interdisciplinares da Comunicação XXXVII Congresso Brasileiro de Ciências da Comunicação - Foz do Iguaçu, PR - 2 a 5/9/2014.

ANDERSON, Hephzibah. 'Expelliarmus!': como Harry Potter influencia a visão política dos Millennials. BBC Brasil News. 20 maio 2018. Disponível em https:/www.bbc.com/portuguese/vert-fut-44089130. Acesso em: 08 jul. 2018.

ATWOOD, Margaret. O conto da aia. São Paulo: Marco Zero, 1987.

BAUMAN, Zygmunt. Identidade. Rio de Janeiro: Jorge Zahar Editor, 2004.

BRAGA, Julio T. Movimentos sociais na era da internet: uma leitura comparativa da ação política nos protestos das Jornadas de Junho, no Brasil, dos Indignados, na Espanha, e do Occupy Wall Street, nos EUA. 2016. 136 f. Dissertação (Mestrado em História) - Programa de Estudos Pós-Graduados em História, Pontifícia Universidade Católica de São Paulo, São Paulo, 2016.

BUTLER, Judith. Bodies in Alliance and the Politics of the Street. Transversala Multilingual Webjournal. European Institute for Progressive Cultural Policies, 2011.

CALHOUN, Craig. Occupy Wall Street in perspective. The British Journal of Sociology, Volume 64, Issue 1, p.26-38, 2013.

CASTELLS, Manuel. Networks of outrage and hope: Social movements in the internet age. John Wiley \& Sons, 2nd edition, 2015.

DAY, Richard. J. F. From Hegemony to Affinity. Cultural Studies, 18(5), 716-748, 2004.

DELLA PORTA, Donatella Alice Mattoni. Spreading protest: social movements in times of crisis. ECPR Press, 2014.

DURKHEIM. Emile. As formas elementares da vida religiosa. São Paulo: Martins Fontes, 2002.

GIDDENS, Anthony. Modernidade e identidade. Rio de Janeiro: Jorge Zahar Editor, 2002.

GOFFMAN, Erving. The presentation of self in everyday life. London: Penguin, 1990.

GONÇALVES, Luana V.; BARBOSA, Flávia C. S. As (re)construções identitárias sobre o sujeito jovem manifestante: mídia, política e formações imaginárias. Revista Advérbio, [S.1.], v. 11, n. 23, dez. 2016.

GRAEBER, David. The new anarchists. New Left Review. 13, January-February, 2002.

CORDERO-GUZMAN, Hector R. Main Stream Support for a Mainstream Movement: The 99\% Movement Comes From and Looks Like the 99\% - Profile of web traffic taken from occupywallst.org. 2011.

HALL, Stuart. A identidade cultural na pós-modernidade. 11 ed. Rio de Janeiro: DP\&A, 2006. 
HOWE, Neil; STRAUSS, William. Millennials Rising: The Next Great Generation. New York: Vintage Books, 2000.

HOWE, Neil; STRAUSS, William. Generations: The History of America's Future, 1584 to 2069. New York: Harper Collins, 1992.

JACOBSSON, Kerstin; LINDBLOM, Jonas. Moral Reflexivity and Dramaturgical Action in Social Movement Activism: The Case of the Plowshares and Animal Rights Sweden. Social Movement Studies: Journal of Social, Cultural and Political Protest, 11:1, 41-60, 2012.

JASPER, James M. Protesto. Uma introdução aos movimentos sociais. Rio de Janeiro: Zahar, 2016.

JURIS, Jeffrey. Reflections on \#Occupy Everywhere: Social Media, Public Space, and Emerging Logics of Aggregation. American Ethnologist, 39 (2):259-279, 2012.

MARTIN, George R.R. As Crônicas de Gelo e Fogo. 5 volumes. 1. ed. Rio de Janeiro: Leya, 2015.

MELUCCI, Alberto. Juventude, tempo e movimentos sociais. In: FÁVERO Osmar; SPÓSITO, Marília Pontes; CARRANO, Paulo; NOVAES, Regina Reys Fávero. (org.). Juventude e

Contemporaneidade. Brasília: UNESCO, MEC, ANPEd, 2007. p.29-45.

MELUCCI, Alberto. A invenção do presente: Movimentos sociais nas sociedades complexas. Petrópolis, RJ: Vozes, 2001

SOARES, Thiago. Abordagens Teóricas para Estudos Sobre Cultura Pop. LOGOS:

Comunicação \& Universidade. v. 2, n. 24, 2014.

SUPER INTERESSANTE. Saiba mais sobre a máscara de Guy Fawkes. 31 out 2016.

Disponível em: https://super.abril.com.br/cultura/mascara-de-guy-fawkes/. Acesso em: 09 jul. 2018 .

TARINGA. Los mejores carteles de protesta ciudadana del 2011. 09 jan. 2012. Disponível em: https://www.taringa.net/posts/info/13635604/Los-mejores-carteles-de-protesta-ciudadanadel-2011.html. Acesso em: 10 jul. 2018.

TARROW, Sidney. The Transnational Activism. Cambridge: Cambridge University Press, 2005 .

TILLY, Charles. Getting it together in Burgundy, 1675-1975. Theory and Society 4(4): 479504, 1977.

UOL EDUCAÇÃO. Protestos estudantis no Chile. 14 jul. 2011. Disponível em:

https://educacao.uol.com.br/album/chile_protestos_educacao_album.htm\#fotoNav=60. Acesso em: 11 jul. 2018.

VAGIANOS, Alanna. Estas mulheres receberam Donald Trump vestidas como Offred, de 'Handmaid's Tale'. USHUFFPOST BRASIL. 06 jul. 2017. Disponível em:

https:/www.huffpostbrasil.com/2017/07/06/estas-mulheres-receberam-donald-trump-vestidascomo-offred-de_a_23019669/. Acesso em: 21 set. 2020. 
WEISS, Raquel A. As Manifestações Sob a Ótica da Sociologia da Moral. In: CATTANI, Antonio David. (Org.). \#protestos - Análises das Ciências Sociais. 1 ed. Porto Alegre: Tomo, 2014, v., p. 93-102.

WERNECK, Paulo; MARTÍ, Silas. Referências visuais dos protestos extrapolam repertório típico da esquerda. FOLHA DE S.PAULO. \#Olhodarua. SP: Ilustrada, 23/06/2013.

Disponível em: https://m.folha.uol.com.br/ilustrada/2013/06/1298999-referencias-visuais-dosprotestos-extrapolam-repertorio-tipico-da-esquerda.shtml. Acesso em: 21 set. 2020.

WESCHENFELDER, Gelson Vanderlei. Os super-heróis e esta tal de filosofia. REI - Revista de Educação do IDAU. Vol. 7 - No 15 - Janeiro-Junho, 2012.

Recebido em 26/08/2019.

Aprovado em 04/06/2020. 